\title{
Effectiveness of the multidimensional ergonomic intervention model to reduce musculoskeletal discomfort among street sweepers in Chiang Rai Province, Thailand
}

This article was published in the following Dove Press journal:

Risk Management and Healthcare Policy

9 December 2016

Number of times this article has been viewed

\section{Kanjanar Pintakham ${ }^{1,2}$ \\ Wattasit Siriwong' \\ 'College of Public Health Sciences, Chulalongkorn University, Bangkok, ${ }^{2}$ School of Health Science, Chiang Rai Rajabhat University, Chiang Rai, Thailand}

\begin{abstract}
The aim of this study was to evaluate the effectiveness of multidimensional ergonomic intervention (MEI) model to reduce musculoskeletal discomfort (MSD) among street sweepers. A quasi-experimental study was conducted in Chiang Rai Province. The MEI model was designed on the basis of four core components: cognitive behavior therapy, ergonomic education training, stretching exercise, and the foam sleeve broom handle grip. Seventy-five street sweepers volunteered for the screening process on MSD of having level score $\geq 4$ by physiotherapist. Face to face interviews were used mainly in order to diagnose MSD. Physical examination was performed by physiotherapist and physical performance by sports scientist. The findings showed that the MEI model among the intervention group significantly reduced MSD compared with that among control group at exit model and follow-up $(P<0.01)$. This research suggests that the MEI model was appropriate to reduce MSD associated with repetitive movement and awkward postures on task.
\end{abstract}

Keywords: repetitive movement, cognitive behavior therapy, stretching exercise, street sweepers

\section{Introduction}

Street sweepers are behind enhancing the traffic safety by removing harmful pollutants and preventing illnesses or diseases from wastes such as garbage, sand, soil, and dust in the municipality. ${ }^{1}$ In general, street sweepers use brooms and a dustpan for cleaning wastes including garbage, sand, soil, and stone. They are exposed to hazards directly and indirectly, which may affect their health. ${ }^{2}$ Also, work-related musculoskeletal discomfort (MSD) among street sweepers was prevalent worldwide. ${ }^{3}$ Prevalence of MSD among street sweepers is $65.00 \%$ in Mansoura, Egypt ${ }^{4}$ and $49.20 \%$ in Brazil. ${ }^{5}$ In Thailand, it is reported at $79.00 \%$ in Hat Yai Municipality, Songkhla Province, ${ }^{6} 79.12 \%$ in the past 7 days and $85.71 \%$ in the past 12 months in Bangkok $^{7}$, and $88.00 \%$ from screening survey in Chiang Rai Municipality, Chiang Rai Province. ${ }^{8}$ The primary risk factors for MSD are work conditions including awkward posture, repetitive motion, static postures, and forceful exertions. ${ }^{9,10}$ The occupation-related MSD among street sweepers are repetitive movement because of broom sweeping and bending back for removing garbage on walking areas. Repetitive movement conditions, using upper limb frequently, lead to MSD among street sweepers. ${ }^{11}$. MSD often involves wrist, elbow, shoulder, and back being exposed over time because of repetitive movement, awkward postures, and forceful exertions. ${ }^{12}$ The musculoskeletal disorder is regarded
Correspondence: Wattasit Siriwong College of Public Health Sciences, Chulalongkorn University, Bangkok, Thailand

Tel +6622188184

Fax +6622556046

Email wattasit.s@chula.ac.th 
as a multifactorial causation including physical or mechanical factors, psychosocial factors or organizational, and individual or personal factors. Moreover, awkward and static postures, repetitive handling, repetitive or monotonous work, demanding, straining work, lack of recreation times, high time pressure, frequent overtime hours, and reduced physical capacity are all risk factors that lead to musculoskeletal disorders. ${ }^{13}$

According to The National Institute for Occupational Safety and Health, the intervention for example safety training, safety policies, and safety procedures can improve musculoskeletal health among workers. Multidimensional interventions are more effective than unidimensional interventions. ${ }^{14}$ Therefore, the intervention model was designed as an integration of cognitive behavior therapy (CBT), ergonomic education training, stretching exercise, and adding a foam sleeve to the broom handle grip with the expectation that it would reduce MSD among street sweepers. Multidimensional ergonomic intervention (MEI) model was designed according to the Occupational Safety and Health Administration's recommendation - that the training be a significant element of the ergonomics process. Training information should include risk of ergonomics issues in the workplace and should be in a plain language that workers understand. Adjusting of equipment or tools and improving awareness of safe work practices are effective factors that reduce MSD and improve work practices. ${ }^{15}$

However, there was a limitation of existing interventions for reducing occupation-related MSD. ${ }^{16}$ According to Yogesh and Zodpey, there were a few ergonomics training research studies on reducing and preventing health risk in street sweepers. ${ }^{17}$ Also in Thailand, only a few ergonomic programs had conducted research studies on techniques that reduce MSD among street sweepers. ${ }^{6,7}$ Therefore, this study integrated four elements including CBT, ergonomic education training, stretching exercise, and adding a foam sleeve handle grip on the model. The aim of this study was to evaluate the effectiveness of MEI model to reduce MSD among street sweepers in the Chiang Rai Municipality.

\section{Methods}

\section{Study population}

A quasi-experimental study was applied in Chiang Rai Province, Thailand. Four subdistricts including Wiang, Robe Wiang, Rimkok, and Sansai were selected to be the research areas. All 75 participants were full time workers and had at least 1 year of experience within the Chiang Rai Municipality. Hence, no sample size calculation was required in this study because all the 75 street sweepers in this study area participated in the study. Both male and female street sweepers who were aged between 18 and 60 years participated in the study. These voluntary participants underwent the screening process for MSD performed by physiotherapist, and the results of this assessment were considered as MSD scores. Severity of MSD was asked by the physiotherapist that was followed by physical examination on the range of motion in order to test a discomfort on movement, and it was recorded in a numeric rating scale - a scale from 0 to 10 where 0 is the no MSD and 10 is more MSD. ${ }^{11}$ The MSD cutoff score was $\geq 4$, and the data indicated the mean score of MSD. The risk levels are as follows:

$\begin{array}{ll}\text { Levels } & \text { Severity of MSD levels } \\ 0 & \text { No MSD } \\ 1-3 & \text { Slight MSD } \\ 4-6 & \text { Moderate MSD } \\ 7-9 & \text { High MSD } \\ 10 & \text { Severe MSD }\end{array}$

Inclusion criteria were MSD score determined by physiotherapist $\geq 4$ and no medical history of prohibition of stretching exercises. Exclusion criteria were having problems of musculoskeletal system during the study, such as arm or leg being broken, so forth and could not participate throughout the study. Only 68 street sweepers met these criteria. The study participants were randomly divided into two groups: an intervention group and a control group by geographic areas. The intervention group consisted of 34 street sweepers at Robe Wiang and Sansai subdistricts, and the control group consisted of 34 street sweepers at Wiang and Rimkok subdistricts. None of the participants dropped out during the study period. Written informed consent was received by all participants. The study was ethically approved by the Ethics Review Committee for Research Involving Human Research Subjects, Chulalongkorn University, Thailand. The certificate of approval number is COA No. 135/2557.

\section{Procedures}

\section{Intervention program}

The MEI model was initiated by a suggestion of an article that combination technique intervention can be more effective than the single interventions. The expected benefits were to reduce MSD among street sweepers. In addition, the duration of multidimensional interventions was shorter than that of the single interventions. The MEI model was developed in this study. It consisted of four components, namely, education, CBT, stretching exercise, and foam sleeve broom handle grip. In this study, the educational training is a significant element of the ergonomics process. An occupational health 
nurse train the participants regarding ergonomics for $\sim 1$ hour once a week for 2 weeks including health risk among street sweepers, hazardous street sweeping affects the MSD, consequences of MSD, how MSD can be prevented, ergonomic safety working practice, and posture of work. Moreover, a psychiatric nurse train the participants regarding CBT for $\sim 1$ hour once a week for 2 weeks. Training information should involve CBT related to prevent MSD, concept of thinking, self-esteem, coping skill-related MSD, and changes your thought related ergonomic safety. CBT is an important technique that is used to motivate healthy thinking referring to healthy feeling and behaviors in the workplace..$^{15}$ In addition, it involves emotion and actions of situation responses that lead to adaptation of life events. ${ }^{18}$ Hence, it focuses on the interaction between thinking, feeling, and behavior that is usually linked with current problems and the limited period of time. ${ }^{18,19}$ It can prevent asymptomatic return of human, awareness of safety practices, and sustainability in the model. Stretching exercises are effective to reduce MSD and pain related to static posture and repetitive movement. The participants were informed to stretch in an exercise for $\sim 30$ minutes three times a week for 12 weeks at Wat Dong Nong Ped crematorium supported by municipality staff. Choi and Woletz suggested that stretching exercises can improve blood circulation, posture, and range of motion. ${ }^{20}$ In addition, it increased flexibility of muscles, tendons, and ligaments. Research indicated that the flexibility and stretching exercise programs can reduce the occurrence of occupation-related MSD and injuries. ${ }^{21}$ The stretching exercise was an effective way to improve MSD related to prolonged activities and or static postures. The intervention program used a foam sleeve on their broom handle to reduce the pressure on the handle and for comfortability. ${ }^{22,23}$ The foam sleeve handle grip was supported for free among participants. The intervention group was from Robe Wiang and Sansai subdistricts, and the control group was from Wiang and Rimkok subdistricts.

This study was a separate part of an activity and meeting among street sweepers; intervention group was conducted at Wat Dong Nong Ped crematorium and control group was conducted at Den Ha crematorium. Both the areas were $\sim 4 \mathrm{~km}$ apart, which would prevent an interaction between intervention and control groups. This place was supported by the municipality, convenient to travel, spacious to conduct activities, and has facilities for participants. This study was performed in $\sim 28$ weeks by providing the intervention model for 12 weeks and follow-up four times at 16th week, 20th week, 24th week, and 28th week. In addition, the model was designed to follow-up every month after intervention as at the first month, second month, third month, and fourth month.
The MEI model started in September until December 2014 and a follow-up from January to April 2015.

The participants in this study were interviewed face to face using questionnaires that included demographic characteristics and MSD. Demographic characteristics including sex, age, education, marital status, smoking, alcohol drinking, exercise, working years, whether took a short break, walking distance, number of brooms changed per month, length of broom, weight of broom, weight of broom and dustpan, proportion (chin height and broom), and proportion (body height and broom).

Musculoskeletal Discomfort Assessment (MSDA) was modified on the basis of the Standardized Nordic Musculoskeletal Questionnaire from Kuorinka et al. ${ }^{24}$ The MSDA was presented by body map and divided into nine body regions including the neck, shoulders, upper back, elbows, lower back, wrists and hands, hip and thighs, knees, and ankles and feet in the last week.

The content validity of the questionnaire was assessed by three experts: one ergonomic educator, one physiotherapist, and one sports scientist who know Thai language well (process of back translation) in order to check for appropriateness in terms of concepts, language, and suggestions. Results in this study showed 1.00 of MSDA. The questionnaires were tested with 30 street sweepers who were working in Phayao Municipality in Phayao Province and who had similar characteristics with the street sweepers in the intervention municipality. The experimental tools were revised on the basis of the expert's recommendation, the tools were tested among 30 street sweepers who were of similar characteristics with sampling street sweepers in the other municipality. Cronbach alpha coefficient in this study was 0.93 of MSDA.

\section{Physical examinations}

The participants were asked about the severity of their physical conditions by the physiotherapist, and it was followed by a physical examination on the range of motions to test movement discomfort which was rated by numeric rating scales, a scale from 0 to 10 where 0 refers to no MSD and 10 more MSD. This physical examination was tested in seven parts of the body including neck, hands/shoulders/scapular, wrists, fingers, hips, knees, and feet.

\section{Physical performance}

The participants in the study were selected to test the physical performance by using arm curl test that dumbbells to test the muscular strength and endurance to do as many arm curls as possible in 30 seconds which is appropriate among street sweepers by sports scientist. Criterion performance scores 
of arm curl test $<11$ in the both male and female mean risk of upper body strength. The arm curl test is significant to assess the upper body strength and is needed in order to assess other activities involving lifting and carrying things such as sweeping. ${ }^{25}$ Sit-ups in 30 minutes was performed to assess the muscular strength and endurance on lower body strength, which was appropriate among street sweepers, by sports scientist. ${ }^{26}$ Criterion performance scores of $<8$ for sit and stand on the chair in both male and female mean risk of upper body strength.

\section{Statistical analysis}

The data were analyzed using SPSS v.17 (Chulalongkorn University license). The descriptive statistics and inferential statistics were analyzed and interpreted as frequencies, percentage, mean, and standard deviation (SD). Chi-square and independent $t$-test were used to compare the differences of demographic data between the intervention group and the control group. Repeated measurement analysis of variance was used to assess the effectiveness of MEI model across the baseline, exit model (twelfth week) and follow-up including the first follow-up (16th week), second follow-up (20th week), third follow-up (24th week), and fourth follow-up (28th week).

\section{Results}

Baseline characteristics and categorical and continuous independent variables were compared between the intervention group and the control group in Tables 1 and 2, respectively. Comparing the characteristics among street sweepers between the intervention and control groups showed no significant differences for most characteristics. Similarly, the characteristics of street sweepers were comparable between the intervention and control groups at the baseline.

Figure 1 shows prevalence rates of MSD in the past 7 days between intervention and control groups at baseline, the exit model, first, second, third, and fourth follow-up. The baseline data indicated that $59.02 \%$ (intervention group) and $57.64 \%$ (control group) of street sweepers had MSD. At the exit MEI model, the prevalence rates of MSD were $45.88 \%$ (intervention group) and $66.27 \%$ (control group). The prevalence rates of MSD decreased in both the groups after the exit model (four times follow-up).

Table 3 shows the comparison of MSD score by physiotherapist between intervention and control group (at the baseline, the exit model, first, second, third, and fourth follow-up. At the baseline point, there was no significant difference of MSD score between intervention (mean $=7.21, \mathrm{SD}=0.98$ ) and control groups ( mean $=7.24, \mathrm{SD}=0.92$ ). However, there were significant differences in mean MSD score from exit
Table I Baseline characteristics compared between the intervention group and control group among street sweepers: categorical independent variables

\begin{tabular}{|c|c|c|c|c|c|}
\hline \multirow[t]{2}{*}{ Characteristics } & \multicolumn{2}{|c|}{$\begin{array}{l}\text { Intervention } \\
(\mathrm{n}=34)\end{array}$} & \multicolumn{2}{|c|}{$\begin{array}{l}\text { Control } \\
(n=34)\end{array}$} & \multirow[t]{2}{*}{$P$-value* } \\
\hline & $\mathbf{n}$ & $\%$ & $\mathbf{n}$ & $\%$ & \\
\hline Sex & & & & & 0.377 \\
\hline Male & 5 & |4.7| & 4 & $1 \mathrm{I} .76$ & \\
\hline Female & 29 & 85.29 & 30 & 88.24 & \\
\hline Education & & & & & 0.111 \\
\hline Primary school & 27 & 79.41 & 31 & 91.18 & \\
\hline Secondary school & 7 & 20.59 & 3 & 8.82 & \\
\hline Marital status & & & & & 0.752 \\
\hline Married & 31 & 91.18 & 33 & 97.06 & \\
\hline Widowed/divorced/separated & 3 & 8.82 & 1 & 2.94 & \\
\hline Smoking & & & & & 0.595 \\
\hline No & 30 & 88.23 & 32 & 94.12 & \\
\hline Yes & 4 & 11.77 & 2 & 5.88 & \\
\hline Drinking & & & & & 0.650 \\
\hline Never & 32 & 94.12 & 31 & 91.18 & \\
\hline Sometimes & 2 & 5.88 & 3 & 8.82 & \\
\hline Take a break & & & & & 0.169 \\
\hline No & 27 & $79.4 I$ & 28 & 82.35 & \\
\hline Yes & 7 & 20.59 & 6 & 17.65 & \\
\hline Exercise & & & & & 0.595 \\
\hline Never & 30 & 88.24 & 32 & 94.12 & \\
\hline Work out I-2 times/week & 4 & 11.76 & 2 & 5.88 & \\
\hline
\end{tabular}

Note: *Significant at $P<0.05, \chi^{2}$ test.

model, first, second, third, and fourth follow-up $(P<0.05$, independent $t$-test).

Table 4 shows the comparison of musculoskeletal upper body strength score by sports scientist between the intervention $(n=34)$ and control groups $(n=34)$ at the baseline, exit model, first, second, third, and fourth follow-up. At the baseline point, there was no difference in the upper body strength score between the intervention (mean $=9.65, \mathrm{SD}=1.04)$ and control groups $($ mean $=9.62, \mathrm{SD}=1.30)$, and the mean difference was 0.02 . However, there were significant difference in the mean upper body strength score from exit model, first, second, third, and fourth follow-up.

Table 5 shows the comparison of musculoskeletal lower body strength score by sports scientist between the intervention $(n=34)$ and control groups $(n=34)$ at the baseline, exit model, first, second, third, and fourth follow-up. At baseline point, there was no difference in the lower body strength score between the intervention (mean $=10.24, \mathrm{SD}=1.46$ ) and control groups (mean $=10.21, \mathrm{SD}=1.37$ ), mean of difference was 0.02 . However, there were significant difference in the mean lower body strength score from exit model, first, second, third, and fourth follow-up.

Table 6 shows significant difference in the effects of MEI model to reduce MSD among street sweepers on changes in the MSD mean score between the intervention and control 
Table 2 Baseline characteristics compared between the intervention group and control group among street sweepers: continuous independent variables

\begin{tabular}{|c|c|c|c|c|c|}
\hline \multirow[t]{2}{*}{ Characteristics } & \multicolumn{2}{|c|}{ Intervention $(n=34)$} & \multicolumn{2}{|c|}{ Control $(n=34)$} & \multirow[t]{2}{*}{$P$-value } \\
\hline & Mean & $\pm \mathrm{SD}$ & Mean & \pm SD & \\
\hline Age (years) & 47.59 & 7.25 & 47.7I & 8.01 & 0.337 \\
\hline $\begin{array}{l}\text { Range }(\max =60 \\
\min =27)\end{array}$ & \multicolumn{2}{|l|}{$28-59$} & \multicolumn{2}{|l|}{$26-60$} & \\
\hline Working years & 14.74 & 7.57 & 15.03 & 8.94 & 0.824 \\
\hline Range & \multicolumn{2}{|l|}{$1-37$} & \multicolumn{2}{|l|}{$1-38$} & \\
\hline $\begin{array}{l}\text { Body mass index } \\
\left(\mathrm{kg} / \mathrm{m}^{2}\right)\end{array}$ & 25.10 & 4.38 & 24.83 & 3.96 & 0.237 \\
\hline Range & \multicolumn{2}{|c|}{$17.50-34.90$} & \multicolumn{2}{|c|}{$18.60-39.80$} & \\
\hline \multicolumn{5}{|l|}{ distance(km) } & 0.209 \\
\hline Range & $\mathrm{I}-3$ & & $\mathrm{I}-3$ & & \\
\hline \multicolumn{6}{|l|}{ month } \\
\hline Range & $1-3$ & & $\mathrm{I}-3$ & & \\
\hline \multicolumn{6}{|l|}{ broom(cm) } \\
\hline Range & \multicolumn{2}{|l|}{$140-200$} & \multicolumn{2}{|c|}{$145-182$} & \\
\hline $\begin{array}{l}\text { Weight of } \\
\operatorname{broom}(g)\end{array}$ & 798.53 & 152.99 & 838.24 & 34.87 & 0.393 \\
\hline Range & \multicolumn{2}{|c|}{$550-1,000$} & \multicolumn{2}{|c|}{$600-1,000$} & \\
\hline $\begin{array}{l}\text { Weight of broom } \\
\text { and dustpan }\end{array}$ & I,725 & 205.33 & 1,750 & 192.27 & 0.562 \\
\hline Range (g) & \multicolumn{2}{|c|}{$1,300-2,000$} & \multicolumn{2}{|c|}{$1,350-2,000$} & \\
\hline Proportion (chin & 123.56 & 11.80 & 121.85 & 10.17 & 0.262 \\
\hline \multicolumn{6}{|c|}{ height and broom) } \\
\hline Range $(\mathrm{cm})$ & \multicolumn{2}{|c|}{$101.96-153.85$} & \multicolumn{2}{|c|}{$106.67-146.34$} & \\
\hline $\begin{array}{l}\text { Proportion (tall } \\
\text { and broom) }\end{array}$ & 106.98 & 10.08 & 105.83 & 8.44 & 0.281 \\
\hline Range & \multicolumn{2}{|c|}{$90.70-134.23$} & \multicolumn{2}{|c|}{$93.54-126.76$} & \\
\hline
\end{tabular}

Note: *Significant at $P<0.05$, $t$-test.

Abbreviations: SD, standard deviation; min, minimum; max, maximum. groups at baseline, exit model, first, second, third, and fourth follow-up ( $F=474.73, P \leq 0.0001)$. Similarly, within subjects testing showed significantly different effects of MEI model on changes in the MSD mean score over six time points $(F=79.22, P \leq 0.0001)$. There were significant differences between the MSD mean score in the intervention and control groups by time interaction ( $P \leq 0.0001$, independent $t$-test).

\section{Discussion}

A quasi-experimental study was designed to measure and evaluate the effectiveness of a MEI model, which was intended to reduce MSD among street sweepers in Chiang Rai Province, Thailand. The intervention was associated with factual and statistical significance of the MEI model on decreasing MSD. The MEI model was associated with substantial improvements in physical performance (upper and lower body strength scores) and with the reduction of severity on the physical conditions related to MSD. Moreover, it was reported that the prevalence rates of MSD decreased after the implementation of the model by MSDA. The findings of this study raise confidence that MEI model-targeted intervention can be effective on reducing MSD among street sweepers.

As mentioned earlier, there were significant differences in the effectiveness of MEI model to reduce MSD among street sweepers between the intervention and control groups in 12 , $16,20,24$, and 28 weeks. Therefore, the MEI model resulted in the change in prevalence rate of MSD. The majority of prevalence rates of MSD was ranked as follows: wrists/hands, shoulders, and neck. Tsuritani et al found that the majority

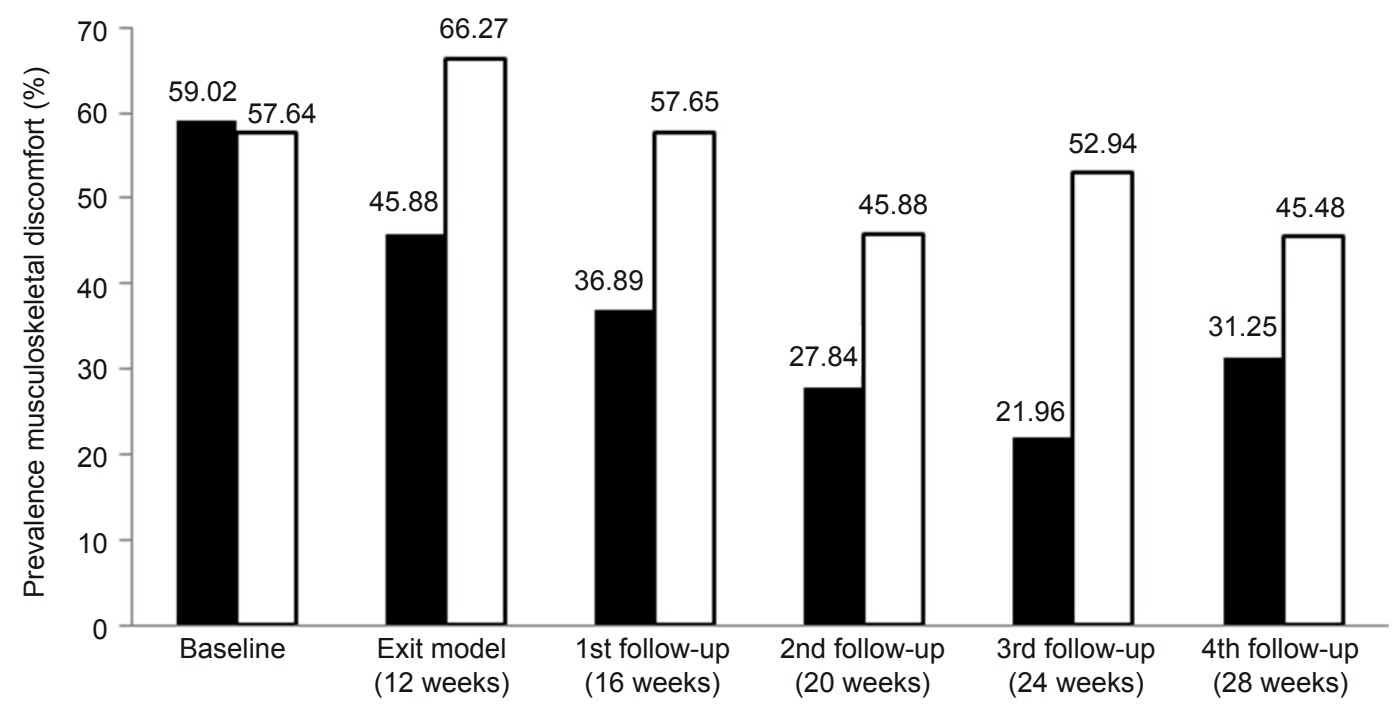

Intervention

Control

Figure I Comparing the prevalence of musculoskeletal discomfort in the past 7 days between the intervention $(n=34)$ and control groups ( $n=34$ ). 
Table 3 Comparing musculoskeletal discomfort score by physiotherapist between the intervention $(n=34)$ and control groups $(n=34)$

\begin{tabular}{lllll}
\hline \multirow{2}{*}{ Time of data collection } & \multicolumn{2}{l}{ Musculoskeletal discomfort (score) } & Mean difference & $\mathbf{9 5 \%} \mathbf{C l}$ \\
\cline { 2 - 4 } & Intervention (mean \pm SD) & Control (mean \pm SD) & & 0.49 to 0.43 \\
\hline Baseline & $7.21 \pm 0.98$ & $7.21 \pm 0.87$ & -0.06 & -2.33 to $-1.55^{*}$ \\
Exit model (12 weeks) & $5.62 \pm 0.85$ & $7.53 \pm 0.73$ & -1.92 & -3.13 to $-2.40^{*}$ \\
First follow-up (16 weeks) & $4.38 \pm 0.78$ & $7.15 \pm 0.77$ & -2.75 & -3.97 to $-3.21^{*}$ \\
Second follow-up (20 weeks) & $3.44 \pm 0.79$ & $7.03 \pm 0.80$ & -3.59 & -4.36 to $-3.6 I^{*}$ \\
Third follow-up (24 weeks) & $3.26 \pm 0.79$ & $7.24 \pm 0.70$ & -3.97 & -4.00 to $-3.30^{*}$ \\
Fourth follow-up (28 weeks) & $3.44 \pm 0.71$ & $7.06 \pm 0.78$ & -3.62 & \\
\hline
\end{tabular}

Note: *Significant at $P<0.05$, using independent $t$-test.

Abbreviations: $\mathrm{Cl}$, confidence interval; SD, standard deviation.

Table 4 Comparing upper body strength score by sports scientist between the intervention $(n=34)$ and control groups ( $n=34)$ at the baseline, exit model, first, second, third, and fourth follow-up

\begin{tabular}{|c|c|c|c|c|}
\hline \multirow[t]{2}{*}{ Time of data collection } & \multicolumn{2}{|c|}{ Musculoskeletal strength (score) } & \multirow[t]{2}{*}{ Mean difference } & \multirow[t]{2}{*}{$95 \% \mathrm{Cl}$} \\
\hline & Intervention (mean \pm SD) & Control (mean \pm SD) & & \\
\hline Baseline & $9.65 \pm 1.04$ & $9.62 \pm 1.30$ & 0.02 & -0.54 to -0.60 \\
\hline Exit model (12 weeks) & $11.94 \pm 1.18$ & $10.29 \pm 1.00$ & 1.65 & 1.12 to $2.18^{*}$ \\
\hline First follow-up (16 weeks) & $12.56 \pm 1.02$ & $10.03 \pm 1.09$ & 2.53 & 2.02 to $3.04 *$ \\
\hline Second follow-up (20 weeks) & $13.00 \pm 0.92$ & $9.94 \pm 0.98$ & 3.06 & 2.60 to $3.52^{*}$ \\
\hline Third follow-up (24 weeks) & $|3.2| \pm 0.9 \mid$ & $10.12 \pm 0.81$ & 3.09 & 2.67 to $3.5 \mathrm{I} *$ \\
\hline Fourth follow-up (28 weeks) & $12.94 \pm 0.78$ & $9.91 \pm 1.08$ & 3.03 & 2.57 to $3.49 *$ \\
\hline
\end{tabular}

Note: *Significant at $P<0.05$, using independent $t$-test.

Abbreviations: $\mathrm{Cl}$, confidence interval; $\mathrm{SD}$, standard deviation.

Table 5 Comparing lower body strength score by sports scientist between the intervention $(n=34)$ and control group ( $\mathrm{n}=34)$ at the baseline, exit model, first, second, third, and fourth follow-up

\begin{tabular}{|c|c|c|c|c|}
\hline \multirow[t]{2}{*}{ Time of data collection } & \multicolumn{2}{|c|}{ Musculoskeletal strength (score) } & \multirow[t]{2}{*}{ Mean difference } & \multirow[t]{2}{*}{$95 \% \mathrm{Cl}$} \\
\hline & $\begin{array}{l}\text { Intervention } \\
(\text { mean } \pm \text { SD) }\end{array}$ & $\begin{array}{l}\text { Control } \\
(\text { mean } \pm \text { SD) }\end{array}$ & & \\
\hline Baseline & $10.24 \pm 1.46$ & $10.21 \pm 1.37$ & 0.02 & -0.66 to -0.72 \\
\hline Exit model ( 12 weeks) & $11.79 \pm 1.43$ & $10.50 \pm 0.93$ & 1.29 & $0.7 \mathrm{I}$ to $1.88^{*}$ \\
\hline First follow-up ( 16 weeks) & $12.94 \pm 0.95$ & $10.24 \pm 0.86$ & 2.71 & 2.27 to $3.14^{*}$ \\
\hline Second follow-up ( 20 weeks) & $13.38 \pm 0.78$ & $9.85 \pm 0.78$ & 3.53 & 3.15 to $3.9 I^{*}$ \\
\hline Third follow-up (24 weeks) & $13.76 \pm 0.74$ & $10.03 \pm 0.72$ & 3.73 & 3.38 to $4.09 *$ \\
\hline Fourth follow-up (28 weeks) & $13.18 \pm 0.83$ & $9.94 \pm 0.81$ & 3.23 & 2.84 to $3.62 *$ \\
\hline
\end{tabular}

Note: *Significant at $P<0.05$, using independent $t$-test.

Abbreviations: $\mathrm{Cl}$, confidence interval; $\mathrm{SD}$, standard deviation.

Table 6 Effectiveness of the MEl model for the mean MSD score between the intervention and control groups of street sweepers $(n=68)$

\begin{tabular}{llllll}
\hline Source & SS & df & MS & F & P-value \\
\hline Between subjects & & & & & \\
Intervention & 717.35 & $\mathrm{I}$ & 717.35 & 474.73 & $<0.000 I^{* *}$ \\
Error & 99.73 & 66 & $1.5 \mathrm{I}$ & & \\
Within subjects* & & & & & \\
Time & 239.45 & 2.47 & 96.82 & 101.96 & $<0.000 I^{* *}$ \\
Intervention* time & 186.04 & 2.47 & 75.22 & 79.22 & $<0.000 I^{* *}$ \\
Error & 155.01 & 163.23 & 0.95 & & \\
\hline
\end{tabular}

Notes: *Greenhouse-Geisser; **significant at $P<0.0$ I.

Abbreviations: $d f$, degrees of freedom; MEI, multidimensional ergonomic intervention; MSD, musculoskeletal discomfort; SS, sum of squares; MS, mean squares. of prevalence of MSD was ranked as follows: lower back, shoulders, legs, neck, and upper back among middle-aged women in Japan. ${ }^{27}$ The research study investigated the prevalence and related factors of MSD among road sweepers in Bangkok and showed that the most of the body region were shoulders and knees. ${ }^{7}$ Moreover, musculoskeletal disorders often involved wrist, elbow, shoulder, and back while exposed over time in repetitive movement, awkward postures, static postures, and forceful exertions, ${ }^{28}$ which are the risk factors of MSD. ${ }^{10}$ Occupation-related MSD among street sweepers was due to repetitive movement from using broom sweeping, 
bending back for removing garbage, and walking areas. The MSD score indicated significant differences of MEI model on changes in mean MSD scores between the intervention and control groups at baseline, exit model, first, second, third, and fourth follow-up. MSD score showed high risk levels of MSD. Demure et al indicated that an ergonomic intervention was associated with the reduction of discomfort scores. ${ }^{29}$ MSD by physiotherapists showed similarities between the intervention and control groups at the baseline point. There were significantly different effects of the MEI model on changes in mean MSD score between the intervention and control groups at baseline, exit model, first, second, third, and fourth follow-up. Similarly, subjects' tests showed significantly different effects of the MEI model on changes in mean MSD score over six time points. MSD score was determined by finding the severity on physical conditions including modified discomfort using a numeric rating scale, a scale from 0 to 10 , where 0 referred to no MSD and 10 more MSD. The resultant mean MSD score in the intervention group was 7.21 and that in the control group was 7.24, which was referred as high risk level MSD. The average of the mean scores for MSD decreased after MEI model and follow-up, which shows a change from high risk to slightly risk MSD in this study.

The MEI model consisted of four integrated components: 1) CBT, 2) ergonomic education training, 3) stretching exercises, and 4) adding foam sleeve handle grip. The MEI model can be generalized to street sweepers in another municipality because the context of street sweepers was similar such as $\sim 1-3 \mathrm{~km}$ for response street sweeping distance in daily work, and same posture in activities including street sweeping distance and bending back. For sustainable programs, the MEI model should be provided among street sweepers during work, and new street sweepers should also be trained. However, the municipalities need to provide the information regarding the costs of MEI model for providing free foam sleeve handle broom among the street sweepers. This study designed a smooth foam sleeve that should be added on to the handle of the broom, and free foam sleeve was provided with the expectation to reduce pressure compression on the hand, provide nonslip handles, and increase the comfortability on the hand-grip of the broom for street sweepers. Innovation broom handle grip could be applied/ added to any street sweepers for daily used. It is easy to use, comfortable, and durable.

\section{Conclusion}

Findings showed that most of the variables among street sweepers were comparable between the intervention and control groups. There were no differences in characteristics among street sweepers and no impact of imbalance baseline characteristics in both the groups (intervention and control groups). This study conducted MEI model that consisted of four integrated components: 1) CBT, 2) ergonomic education training, 3) stretching exercise, and 4) innovative foam sleeve handle grip. All the outcomes reported that the effectiveness of the MEI model reduced MSD. The MEI model will be developed to ease and combine and produce a booklet for implementation in real situations; such a resource will be provided to other municipalities as well. The model will train the staff of other municipalities from the research study. Generally, the municipality staff can conduct the ergonomic education training and stretching exercises. Innovation foam sleeve handle broom can be managed from municipality except CBT which can be provided from hospital nurses.

\section{Study limitations}

1. Sex imbalance: there were 59 female participants, with only nine male participants. Women have high tolerance levels and good concentration, which make them sweep better than men as the conditions of the work were mainly sweeping and collecting waste into bins, and hence these activities require female labor force. Whereas collecting municipal solid waste located in the local disposal sites and dump sites requires male labor force.

2. Possibility of contamination might have occurred. This study was conducted in the Chiang Rai's Muang District area that may have an interaction between intervention and control groups during the activities. However, the street sweepers normally worked in their separate assigned zones and hardly communicated and/or had face to face contact with one another.

3. Outside information on "Health service", social/cultural interactions, and communication technology may have influenced and interfered with the results.

\section{Acknowledgments}

This study received a generous support of funding from the 90th Anniversary of Chulalongkorn University Fund and the Grant for International Research Integration: Chula Research Scholar (GCURS_59_06_79_01) Ratchadaphiseksomphot Endowment Fund. We would like to thank the College of Public Health Science, Chulalongkorn University, Bangkok; Chiang Rai Municipality, Chiang Rai; and School of Health Science, Chiang Rai Rajabhat University, Chiang Rai for their support. This research article is a part of Kanjanar Pintakham's dissertation entitled "Effectiveness of the Multidimensional Ergonomic Intervention (MEI) Model to Reduce Musculoskeletal 
Discomfort among Street Sweepers", Graduate School, Chulalongkorn University. Also, this study was presented at the 7 th International Conference on Public Health Among Greater Mekong Sub-Regional Countries on September 26-27, 2015, at Imperial Hotel, Hue city, Vietnam, as an oral presentation with interim findings. The abstract of the oral presentation was published in the conference abstract book.

\section{Disclosure}

The authors report no conflicts of interest in this work.

\section{References}

1. Seera RS. Development of a Street Sweeper Fleet Management System. Las Vegas, NV: University of Nevada; 2005.

2. International Labor Organization. The Baseline Survey of the Occupational Safety and health Conditions of Solid Waste Primary Collectors and Street Sweepers in Addis Ababa. March 2007. Available from http:// www.ait.ac.th/research/ARR\%202007.pdf. Accessed January 52015.

3. Das R, Pradhan S, Mandal S, Ali KM, Maiti S, Ghosh D. Impact of health awareness intervention among women sweepers working under the Midnapore municipality of West Bengal, India. Bangladesh J Med Sci. 2013;12(01):49-54.

4. Mehrdad R, Majlessi-Nasr M, Aminian O, Malekahmadi SSF. Musculoskeletal disorders among municipal solid waste workers. Acta Medica Iranica, 2008;46(3):233-238.

5. Da Silva C, Hoppe A, Ravanello M, Mello N. Medical wastes management in the south of Brazil. Waste Manag. 2005;25(6):600-605.

6. Losakul P, Chanprasit C, Kaewthummanukul T. Health status and health promoting behaviors among street sweepers, Songkhla Province. $J$ Health Sci. 2007;16(3):400-408.

7. Theerawanichtrakul S, Sithisarankul P. Prevalence and related factors of musculoskeletal discomfort among road sweepers in Bangkok. Thammasat Med J. 2014;14(1):27-36.

8. Pintakham K, Taneepanichskul S, Siriwong W. Work related musculoskeletal discomfort among street sweepers in Chiang Rai Municipality. The 6th International Conference on Public Health among the Greater Mekong Sub-Regional Countries: Health Service Development for a Borderless Community: Human Resource Development for a District Health System; November 6-7; 2014; Khon Kaen, Thailand;124.

9. European Agency for Safety and Health at Work. FACTS 71 Introduction to work-related musculoskeletal disorders; 2007. Available from: http:// osha.europa.eu/publications/factsheets/71. Accessed January 3, 2015.

10. NIOSH. Ergonomic Guidelines for Manual Material Handling was prepared for publication by the Cal/OSHA Consultation Service, Research and Education Unit, Division of Occupational Safety and Health, California Department of Industrial Relations. DHHS (NIOSH) Publication No. 2007-131; 2007.

11. Pintakham K. Effectiveness of the Multidimensional Ergonomic Intervention (MEI) Model to Reduce Musculoskeletal Discomfort among Street Sweepers (doctor of philosophy's thesis). College of Public Health Sciences, Chulalongkorn University; Bangkok, Thailand; 2014.

12. Chaffin DB, Andersson GBJ, Martin BJ. Occupational Biomechanics. 4th ed. Hoboken, NJ: John Wiley \& Sons, Inc; 2006.
13. Robson L, et al. A Systematic Review of the Effectiveness of Training \& Education for the Protection of Workers; Toronto: Institute for Work \& Health. Cincinnati: National Institute for Occupational Safety and Health, 2010. Available from http://www.jstor.org/stable/41508885?seq=1\#page_ scan_tab_contents. Accessed September 10, 2016.

14. Fujishiro K, Weaver JL, Heaney CA, Hamrick CA, Marras WS. The effect of ergonomic interventions in healthcare facilities on musculoskeletal disorders. Am J Ind Med. 2005;48(5):338-347.

15. Occupational Safety and Health Administration (OSHA). Guidelines for Shipyards: Prevention of Musculoskeletal Injuries in Poultry Processing Occupational Safety and Health Administration United States Department of Labor, OSHA 3213; 2008. Available from: https://www.osha. gov/Publications/OSHA3341 shipyard.pdf. Accessed on September 10, 2016.

16. Amick BC III, Robertson MM, DeRango K, et al. Effect of office ergonomics intervention on reducing musculoskeletal symptoms. Spine. 2003;28(24):2706-2711.

17. Yogesh SD, Zodpey SP. Respiratory morbidity among street sweepers working at Hanumannagar Zone of Nagpur Municipal Corporation, Maharashtra. Indian J Public Health. 2007;52(3):147-149.

18. Prendes AG, Resko SM. Cognitive-Behavioral Theory; 2012. Available from: http://www.sagepub.com/upm-data/40689_2.pdf.

19. Freeman JB, Choate-Summers ML, Moore PS, et al. Cognitive behavioral treatment for young children with obsessive-compulsive disorder. Biol Psychiatry. 2007;61(3):337-343.

20. Choi SD, Woletz T. Do stretching programs prevent work-related musculoskeletal disorders. J Safety Health Environ Res. 2010;6(3):1-19.

21. Drennan FS, Ramsay JD, Richey D. Program development-integrating employee safety \& fitness: a model for meeting NIOSH's steps to a healthier US workforce challenge - an aging workforce has become a key driver of high workers. Prof Saf. 2006;51(1):26-35.

22. GripWorks. The leader in hand grips innovation \& design. Gripworks production facility located in St. Louis, Missouri. 2011. Available from: http://www.gripworks.com/grip-sleeve-products.htm. Accessed December 8, 2014.

23. California Department of Industrial Relations. Working Safer and Easier for Janitors, Custodians, and Housekeepers. Division of Occupational Safety and Health, California Department of Industrial Relations Code Section 11096; 2005. Available from: http://www.dir.ca.gov/dosh/ puborder.asp. Accessed December 22, 2014.

24. Kuorinka I, Jonsson B, Kilbom A, et al. Standardised Nordic questionnaires for the analysis of musculoskeletal symptoms. Appl Ergon. 1987;18(3):233-237.

25. Jones CJ, Rikli RE. Measuring functional. JActive Aging. 2002;1:24-30.

26. Panti S. Assessment the performance on elderly. Manual report activities, Chiang Mai University; 2007. Available from http://www.ait.ac.th/ research/ARR\%202007.pdf. Accessed January 5, 2015.

27. Tsuritani I, Honda R, Noborisaka Y, Ishida M, Ishizaki M, Yamada Y. Impact of obesity on musculoskeletal pain and difficulty of daily movements in Japanese middle-aged women. Maturitas. 2002;42(1):23-30.

28. Mahmud N, Kenny DT, Zein RM, Hassan SN. Ergonomic training reduces musculoskeletal disorders among office workers: results from the 6-month follow-up. Malaysian J Med Sci. 2011;18(2):16.

29. Demure B, Mundt KA, Bigelow C, Luippold RS, Ali D, Liese B. Video display terminal workstation improvement program: II. Ergonomic intervention and reduction of musculoskeletal discomfort. J Occup Environ Med. 2000;42(8):792-797. 


\section{Publish your work in this journal}

Risk Management and Healthcare Policy is an international, peer-reviewed open access journal focusing on all aspects of public health, policy, and preventative measures to promote good health and improve morbidity and mortality in the population. The journal welcomes submitted papers covering original research, basic science, clinical and epidemiological

Submit your manuscript here: https://www.dovepress.com/risk-management-and-healthcare-policy-journal

studies, reviews and evaluations, guidelines, expert opinion and commentary, case reports and extended reports. The manuscript management system is completely online and includes a very quick and fair peerreview system, which is all easy to use. Visit http://www.dovepress.com/ testimonials.php to read real quotes from published authors. 